\title{
Opium use reporting error in case-control studies: neighborhood controls versus hospital visitor controls
}

\author{
Elham Mohebbi ${ }^{1,2}$, Hamideh Rashidian ${ }^{1}$, Ahmad Naghibzadeh Tahami ${ }^{3}$, Ali Akbar Haghdoost ${ }^{3}$, Afarin Rahimi-Movaghar ${ }^{4}$, \\ Monireh Sadat Seyyedsalehi ${ }^{1}$, Abass Rezaianzadeh ${ }^{5}$, Maryam Marzban ${ }^{6}$, Abdolvahab Moradi ${ }^{7}$, Mahin Gholipour ${ }^{7}$, \\ Maryam Hadji ${ }^{1,8}$, Farin Kamangar ${ }^{9} *(\mathbb{D})$, Kazem Zendehdel ${ }^{1 *}$ (D)
}

Received: 19 May 2020

Published: 10 May 2021

\section{Abstract}

Background: There are relatively scant data to determine whether hospital visitors could serve as a proper source of controls in case-control studies of illicit drug use. The aim of this study was to evaluate using neighborhood versus hospital visitor controls in reporting opium use.

Methods: We used data from 2 independent case-control studies of cancer in Iran. In the first study, controls were selected from neighborhoods of the patients. For the second one, controls were selected from among hospital visitors. In the latter study, hospital visitors were companions of the patients or others visiting the hospital for reasons other than disease treatment. We used stata (version 12; Stata Corp( for all analyses and with a significance level of 0.05 .

Results: Data from 616 of neighborhood controls and 414 of hospital visitor controls were analyzed. Opium point prevalence among men was significantly higher in hospital visitors than neighborhood controls $(43.3 \%$ vs $32.2 \% ; \mathrm{P}=0.047)$, while the prevalence of cigarette smoking was very similar in both control groups $(46.3 \%$ vs $47.2 \% ; \mathrm{P}=.847)$. Using a logistic regression analysis, in an unadjusted analysis, neighborhood controls were less likely to report opium use in both genders, with (unadjusted OR $=0.77 ; 95 \% \mathrm{CI}$ : $0.59,1)$. After adjusting for potential confounders, the differences of opium use between the 2 control groups became more pronounced (Adjusted OR $=0.26 ; 95 \%$ CI: 0.10, 0.69).

Conclusion: Because of the similarity of reporting cigarette smoking among neighborhood controls but substantially lower reporting of opium use among them, we concluded that neighborhood controls underreport opium use - a sensitive question- and that using neighborhood control biases the findings in case-control studies. Hospital visitor controls may be more appropriate than neighborhood controls for case-control studies of illicit drugs.

Keywords: Substance-Related Disorders, Opium, Case-Control Study, Epidemiologic Studies, Cigarette Smoking, Hospital Visitor Control

Conflicts of Interest: None declared

Funding: This work was supported by the National Institute for Medical Research Development (grant number: 940045). The fundimg bodies had no role in the design of the study and collection, analysis, and interpretation of data, and writing the manuscript.

\section{*This work has been published under CC BY-NC-SA 1.0 license.}

Copyright $\odot$ Iran University of Medical Sciences

Cite this article as: Mohebbi E, Rashidian H, Naghibzadeh Tahami A, Haghdoost AA, Rahimi-Movaghar A, Seyyedsalehi MS, Rezaianzadeh A, Marzban M, Moradi A, Gholipour M, Hadji M, Kamangar F, Zendehdel K. Opium use reporting error in case-control studies: neighborhood controls versus hospital visitor controls. Med J Islam Repub Iran. 2021 (10 May);35:60. https://doi.org/10.47176/mjiri.35.60

Corresponding author: Dr Kazem Zendehdel, kzendeh@sina.tums.ac.ir Dr Farin Kamangar, farin.kamangar@morgan.edu

${ }^{1 .}$ Cancer Research Center, Cancer Institute of Iran, Tehran University of Medical Sciences, Tehran, Iran

2. Department of Pathology, Pathology and Stem Cell Research Center, Afzalipour Medical School, Kerman University of Medical Sciences, Kerman, Iran

3. Modeling in Health Research Center, Institute for Future Studies in Health, Kerman Medical Science University, Kerman, Iran

4. Iranian National Center for Addiction Studies (INCAS), Tehran University of Medical Sciences, Tehran, Iran

5. Colorectal Research Center, Shiraz University of Medical Sciences, Shiraz, Iran

6. Clinical Research Development Center, "The Persian Gulf Martyrs", Bushehr University of Medical Science, Bushehr, Iran

7. Golestan Research Center of Gastroenterology and Hepatology, Golestan University of Medical Sciences, Gorgan, Iran

8. Health Sciences Unit, Faculty of Social Sciences, Tampere University, Tampere, Finland

9. Department of Biology, School of Computer, Mathematical, and Natural Sciences, Morgan State University, Baltimore, MD, USA $\uparrow$ What is "already known" in this topic:

Selecting a comparable control group is a particular issue inherent in case-control studies. The issue is more triggered when the exposure of interest is a sensitive question like opium use. In Iran, some case-control studies of opium use have been performed using neighborhood controls, which may lead to underreporting opium use becuase of social stigma.

\section{$\rightarrow$ What this article adds:}

Hospital visitors could serve as a control group for a casecontrol study of sensitive questions like banned substances (eg, opium).

The prevalence of regular cigarette smoking was similar between hospital visitor controls and neighborhood controls, while regular opium use was underreported by neighborhood controls. Hospital visitor controls were more cooperative than neighborhood controls. 


\section{Introduction}

Case-control studies are designed to be more efficient versions of prospective cohort studies, particularly when the disease is relatively rare. The most appropriate controls are those that accurately represent exposure rates in the base cohort from which the cases come. Despite many years of research, however, the selection of appropriate controls remains a challenge (1-6), particularly when the exposure of interest is a sensitive question, such as using an illicit drug (eg, opium) (7-10).

Researchers may choose to select controls from patients with other diseases in the same clinic or hospital to which the cases are referred (disease controls), friends or family members accompanying patients to the clinic or hospital (hospital visitor controls), or a random sample of the source population from which the cases come (population controls). Each of these methods has its own limitations. Disease controls are relatively accessible, often motivated to participate, and more likely to provide accurate information, but they are also more likely to be exposed to a host of risky behaviors than the source population from which the case come (1), potentially leading to underestimation of the strength of association with the risk factor under study (11). Population controls, on the other hand, are more likely to have exposure levels similar to the source population, but they are less cooperative and may underreport illicit drug use. This underreporting may be more pronounced when interviews are conducted in homes of the neighborhood controls (often so), where they may be heard by friends and family members. They may also fear being investigated for possession of illicit drugs, such as opium, in their homes, which is illegal in some countries like Iran. There is also a high cost to identifying and interviewing such controls in the population, specially when they will be requested to donate biological sample, and their lack of cooperation may lead to selection bias (1).

Hospital visitors (visitor controls) are often reasonably motivated to answer questions relatively accurately because of the relationship they build with providers to their patient, relatively easy to recruit, and are less likely to be overexposed to risky behaviors, as disease controls are. To reduce the potential for overmatching, visitor controls are preferably not selected from friends or family members of cases; rather they are selected from friends or family members of patients with diseases deemed to be unrelated to the exposure of interest.

Opium use is quite common in several areas of Iran, and some studies have suggested that opium use may be associated with higher risk of several adverse health outcomes, such as cancer, cardiovascular diseases, diabetes, and metabolic syndrome (12-20). Therefore, finding the most appropriate type of control focusing on opium is of interest. The aim of this study is to compare 2 control types, neighborhood controls versus visitor controls, with regard to their responses to opium use. To assess and compare the validity of responses, we asked detailed questions about both opium and cigarette use. Cigarette smoking is not stigmatized for men, and possession of cigarettes is not illegal. By contrast, opium use is associated with some level of stigmatization, and opium possession is illegal in Iran, which may cause some legal issues for users, given that users often store some amounts in their home or at work.

\section{Methods}

\section{Study Design}

The 2 control groups came from 2 independent casecontrol studies that were condlucted in Kerman Province, in southeast of Iran, one from 2013 to 2015, and the other from 2016 to 2018 . It is noteworthy that the prevalence of cigarette-smoking and opium use have been stable for the last decade; therefore, the time frame difference of these 2 studies did not bias the comparisons $(7,21)$.

\section{Neighborhood-Based Case-Control Study (Study 1)}

From 2013 to 2015, a population-based case-control study was designed to determine the association of opium use and risk of bladder cancer. All bladder cancer cases who were residents of Kerman province, were able to speak Persian, had a histological diagnosis of cancer within 1 year prior to the interview (incident cases), and were able to undergo an 80-minute interviewing, were eligible. Women who were pregnant or nursing were excluded. Data from 2 sources were used to identify and recruit the large majority of the bladder cancer cases: the Kerman Province cancer registry and records from a provinciallevel referral hospital for treatment of cancer patients, resulting in enrollment of 308 bladder cancer cases. A total of 616 eligible controls (2:1 control-case ratio) were selected from residents of Kerman Province. Controls were cancer free and were individually matched to cases for gender, age ( \pm 2 years), and residential place.

Matching by residential place was done by municipality district, using a predefined plan. Six houses were selected from the main street where the house of cases was located. The interviewers planned the order of approaching the houses. If no eligible controls were found in the first selected house, or the eligible controls refused to participate, the interviewers approached the second designated household, and so forth. This strategy was followed until 2 eligible controls were found for each case. In all, 62 (10\%) invited potential controls refused to participate.

All interviews were done face-to-face in an environment that allowed for uninterrupted privacy. Data were collected using a structured questionnaire that included detailed questions on tobacco, opium use, demographic information, and other relevant data.

\section{Hospital-Based Case-Control Study (Study 2)}

From 2016 to 2018, a multicenter case-control study The Iranian Opium and Cancer (IROPICAN) study - was designed and conducted to assess the association of the lung, colorectal, head and neck, and bladder cancers in 10 
provinces of Iran, including Kerman Province. We used data from controls selected in Kerman Province. Cases were cancer patients admitted to one of the 3 referral cancer care centers in Kerman. Eligibility criteria were the same as the previous study, ie, being Iranian, having received a histological diagnosis of cancer within 1 year prior to the study, ability to speak Persian, and ability to interview for 80 minutes. Women who were nursing or pregnant were not eligible.

Potential controls were healthy hospital visitors who were relatives or friends of hospitalized patients in nononcology wards, or those who visited the hospital for any reasons other than receiving medical service for themselves. Further eligibility criteria were the same as those set for cases, except that the controls had to be absolutely free of any history of cancer. A total of 414 hospital visitors were asked to participate as controls, of whom 25 $(6 \%)$ refused to participate. The controls were frequencymatched to cases by age (5-year intervals; 30 to $75+$ groups), gender, and residential place (Kerman city residence and non-Kerman residence). Trained interviewers gathered tobacco and opium use data at the hospital in face-to-face interviews using structured questionnaires.

Although the duration of sampling was different between the above 2 studies, there was no evidence of a major secular trend in the prevalence of smoking over the duration of these studies. STEPwise approach to surveillance (STEPS), a national survey of chronic disease risk factors in Iran, which was conducted in 2011 and 2016, showed that the overall prevalence of daily smoking was $10.91 \%$ (95\% CI: $9.97 \%, 11.93 \%$ ) in 2011 and $10.08 \%$ (95\% CI: $9.73 \%, 10.43 \%)$ in $2016(22,23)$. Therefore, a difference in sampling period is unlikely to play an explanatory role in our findings.

\section{Opium Use Data}

Opium use was self-reported in both studies. In a previous validation study, we found a high level of sensitivity (77\%) for self-reported opium use among visitor controls, using thin layer chromatography (TLC) to detect morphine metabolites in urine as the gold standard (9). Opium point prevalence was defined as "prevalence of opium use in the six months prior to the survey." A similar definition was used for cigarette smoking.

\section{Statistical Analysis}

The 2 primary exposures of interest were opium use and cigarette smoking in neighborhood and visitor controls. Data were categorized and presented by gender, age, socioeconomic status (SES). An overall SES score was determined using principal components analysis (PCA) by combining the ownership of some assets (dichotomous variables, washing machine, freezer, personal computer, sofa, vacuum cleaner, dishwasher, split air conditioner, owned house, owned car, sponsored by charitable /supporting organizations, complementary insurance). We used chi-square test to compare proportions between groups. The results of Bartlett's test of sphericity and the Kaiser-Meyer-Olkin (KMO) test was 0.83 , indicating that the results were suitable for PCA. Also, the Bartlett's test result was significant, showing that the data were suitable for PCA $(\mathrm{P}>0.1)$.

Analyses were done for all participants together, by subgroups, and for men only. An analysis for men only was useful because: (1) rates of cigarette-smoking and opium use were substantially lower in women, leading to random error; (2) the use of cigarette-smoking may be associated with stigma among women but not in men.

Given the differences between the 2 control groups (neighborhood vs hospital visitor), we used logistic regression to compare opium use among the 2 groups, after adjusting for various potential confounders, including gender, education, age, SES, the area of residence, opium use (yes/no), and cigarette-smoking for adjustment. A Pvalue of less than 0.05 was considered statistically significant. All analyses were performed using Stata (version 12; Stata Corp, College Station, TX, USA).

\section{Ethics Approval and Consent to Participate}

The designing and implementation of both studies were approved by Kerman University of Medical Sciences Ethics Committee (KMU.9421). Because of its multicenter nature, study 2 received additional approval from the Institutional Review Board of the National Institute for Medical Research Development (IR.NIMAD.REC. 1394.027). A written informed consent was obtained from all study participants. After explaining the study, a written consent was obtained from all participants.

\section{Results}

Data from a total of 616 of neighborhood controls and 414 of visitor controls were analyzed. Table 1 compares some basic demographic factors. The majority of the controls in both studies were men, $540(87.7 \%)$ of Study 1 and 307 (74.1\%) of Study 2 participants. Visitor controls were more likely to be younger, have some education, and reside outside Kerman. Marriage rates were similar across both control groups $(\mathrm{p}=0.973)$.

Table 2 illustrates the frequency of use of opium and cigarettes among the 2 control groups. Also, 35\% of visitor controls reported opium use, compared to $29.4 \%$ in the neighborhood controls $(\mathrm{p}=0.171)$. In contrast to opium use, the reported cigarette use was lower among visitor controls (37.0\% vs 41.1\%; $\mathrm{p}=0.424)$ (Table 2).

Male sex was a very strong predictor of using both opium and cigarettes. Because of the relatively low prevalence of opium and cigarette use among women, we repeated all analyses once for men only (Table 3 ). The reported opium use was higher among men visitor controls (43.3\% vs $32.2 \%$; $\mathrm{p}=0.047$ ), while the distribution of cigarette users was similar between neighborhood and visitor controls $(46.3 \%$ vs $47.2 \%$; $=0.847)$. A similar pattern was seen when stratified by other characteristics. While the reported cigarette-smoking was quite comparable across all strata between visitor and neighborhood controls, the reported opium use was substantially lower among neighborhood controls (Table 3). 
Table 1. Characteristics of Neighborhood and Visitor Controls in Kerman Province, Southern Iran

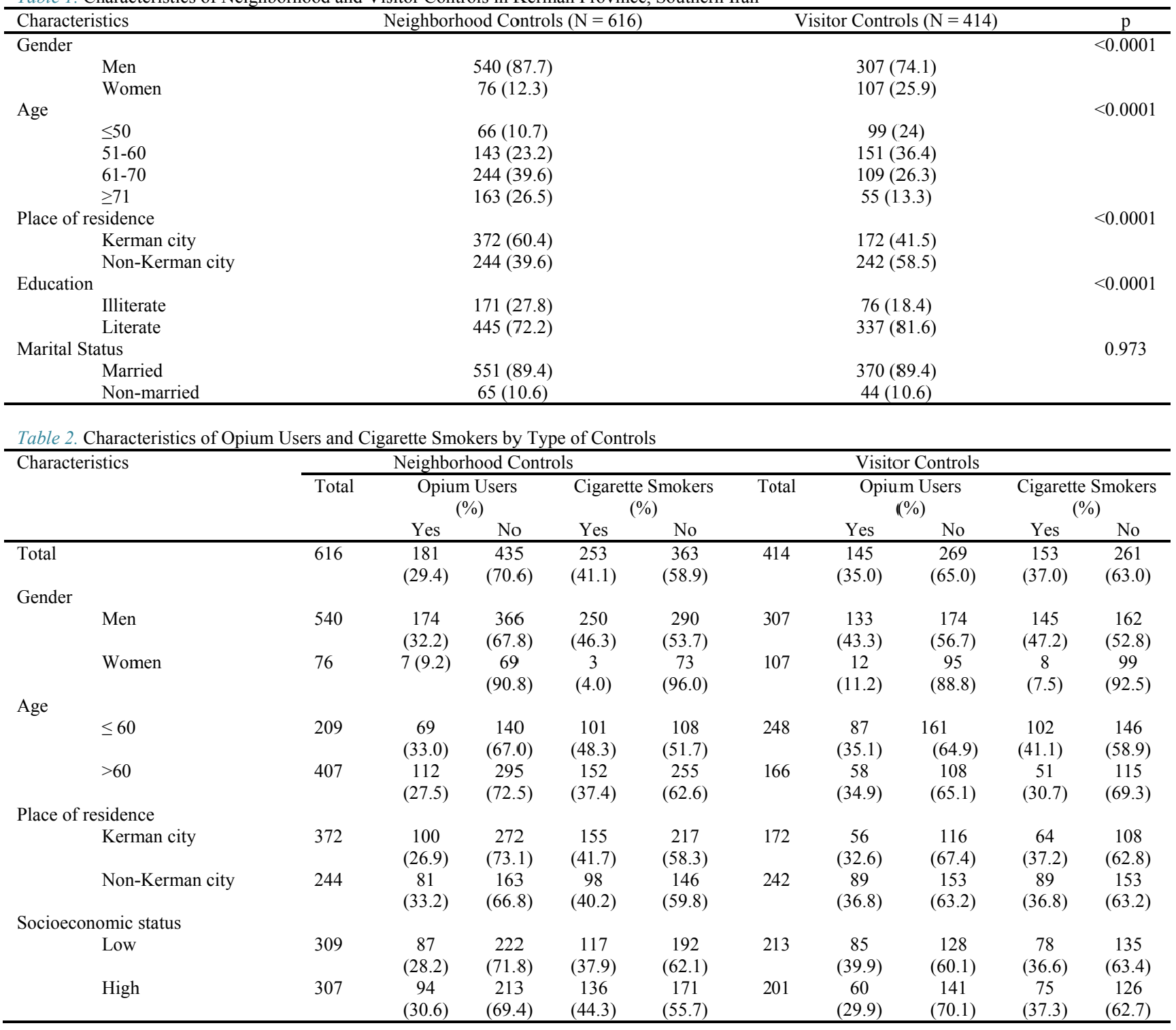

Using a logistic regression analysis, in an unadjusted analysis, neighborhood controls were less likely to report opium use, with unadjusted $\mathrm{OR}=0.77,95 \% \mathrm{CI}$ : $0.59,1.00$. When adjusted for other predictors, including gender, age, area of residence, SES, and cigarette-smoking, the difference became more pronounced with and adjsuted $\mathrm{OR}=0.26,95 \%$ CI: 0.10-0.69 (Table 4).

\section{Discussion}

In this study, the self-reported rates of cigarettesmoking were similar between neighborhood and visitor control groups, but the self-reported rates of opium use were lower among neighborhood controls. When restricting the analysis to men, we saw a similar pattern: nearly $47 \%$ of both groups reported cigarette-smoking, while there was a substantial difference in reporting opium use: $32 \%$ in neighborhood controls compared to $43 \%$ in visitor controls. Adjusting for various characteristics in the logistic regression model made the differences even more pronounced. These results possibly indicate a substantial reporting bias when selecting controls from the neighborhoods with regard to sensitive questions like opium use.

The similarity of the reportied prevalence of cigarettesmoking between visitor and neighborhood controls has some implications. The approximation of cigarettesmoking as a social norm has been demonstrated among some types of controls that was close to the source population $(19,24,25)$. Accordingly, the reporting of cigarettesmoking could be used as the gold standard of reporting illicit substances.

The observed differences of opium use and cigarettesmoking among the 2 series of controls are likely because opium is an illicit substance in Iran, while cigarettes are not. Neighborhood controls are often approached by interviewers who are strangers and aware of the participants' home address. Therefore, the controls may be suspicious of the intentions of interviewers, hence, may be less likely to respond truthfully to questions about opium use. On the other hand, because visitor controls are often seeking 
Table 3. Characteristics of Opium Users and Cigarette Smokers by Type of Controls Among Men

\begin{tabular}{|c|c|c|c|c|c|c|c|c|c|c|}
\hline \multirow[t]{3}{*}{ Characteristics } & \multicolumn{5}{|c|}{ Neighborhood Controls } & \multicolumn{5}{|c|}{ Visitor Controls } \\
\hline & \multirow{3}{*}{$\begin{array}{c}\text { Total } \\
540\end{array}$} & \multicolumn{2}{|c|}{$\begin{array}{c}\text { Opium Users } \\
(\%)\end{array}$} & \multicolumn{2}{|c|}{$\begin{array}{c}\text { Cigarette Smokers } \\
(\%)\end{array}$} & \multirow{3}{*}{$\begin{array}{l}\text { Total } \\
307\end{array}$} & \multicolumn{2}{|c|}{$\begin{array}{c}\text { Opium Users } \\
(\%)\end{array}$} & \multicolumn{2}{|c|}{$\begin{array}{c}\text { Cigarette Smokers } \\
(\%)\end{array}$} \\
\hline & & Yes & No & Yes & No & & Yes & No & Yes & No \\
\hline Total & & $\begin{array}{c}174 \\
(32.2)\end{array}$ & $\begin{array}{c}366 \\
(67.8)\end{array}$ & $\begin{array}{c}250 \\
(46.3)\end{array}$ & $\begin{array}{c}290 \\
(53.7)\end{array}$ & & $\begin{array}{c}133 \\
(43.3)\end{array}$ & $\begin{array}{c}174 \\
(56.7)\end{array}$ & $\begin{array}{c}145 \\
(47.2)\end{array}$ & $\begin{array}{c}162 \\
(52.8)\end{array}$ \\
\hline Age & & & & & & & & & & \\
\hline$\leq 60$ & 183 & $\begin{array}{c}67 \\
(36.6)\end{array}$ & $\begin{array}{c}116 \\
(6.4)\end{array}$ & $\begin{array}{c}101 \\
(55.2)\end{array}$ & $\begin{array}{c}82 \\
(44.8)\end{array}$ & 185 & $\begin{array}{c}83 \\
(44.9)\end{array}$ & $\begin{array}{c}102 \\
(55.1)\end{array}$ & $\begin{array}{c}99 \\
(53.5)\end{array}$ & $\begin{array}{c}86 \\
(46.5)\end{array}$ \\
\hline$>60$ & 357 & $\begin{array}{c}107 \\
(29.9)\end{array}$ & $\begin{array}{c}250 \\
(70.1)\end{array}$ & $\begin{array}{c}149 \\
(41.7)\end{array}$ & $\begin{array}{c}208 \\
(58.3)\end{array}$ & 122 & $\begin{array}{c}50 \\
(41.0)\end{array}$ & $\begin{array}{c}72 \\
(59.0)\end{array}$ & $\begin{array}{c}46 \\
(37.7)\end{array}$ & $\begin{array}{c}76 \\
(62.3)\end{array}$ \\
\hline Place of residence & & & & & & & & & & \\
\hline Kerman city & 338 & $\begin{array}{c}96 \\
(28.4)\end{array}$ & $\begin{array}{c}242 \\
(71.6)\end{array}$ & $\begin{array}{c}154 \\
(45.6)\end{array}$ & $\begin{array}{c}184 \\
(54.4)\end{array}$ & 124 & $\begin{array}{c}51 \\
(41.1)\end{array}$ & $\begin{array}{c}73 \\
(58.9)\end{array}$ & $\begin{array}{c}58 \\
(46.8)\end{array}$ & $\begin{array}{c}66 \\
(53.2)\end{array}$ \\
\hline Non-Kerman city & 202 & $\begin{array}{c}78 \\
(38.6)\end{array}$ & $\begin{array}{c}124 \\
(61.4)\end{array}$ & $\begin{array}{c}96 \\
(47.5)\end{array}$ & $\begin{array}{c}106 \\
(52.5)\end{array}$ & 183 & $\begin{array}{c}82 \\
(44.8)\end{array}$ & $\begin{array}{c}101 \\
(55.2)\end{array}$ & $\begin{array}{c}87 \\
(47.5)\end{array}$ & $\begin{array}{c}96 \\
(52.5)\end{array}$ \\
\hline Socioeconomic status & & & & & & & & & & \\
\hline Low & 270 & $\begin{array}{c}83 \\
(30.5)\end{array}$ & $\begin{array}{c}187 \\
(69.5)\end{array}$ & $\begin{array}{c}116 \\
(43.0)\end{array}$ & $\begin{array}{c}154 \\
(57.0)\end{array}$ & 153 & $\begin{array}{c}35 \\
(22.9)\end{array}$ & $\begin{array}{c}118 \\
(77.1)\end{array}$ & $\begin{array}{c}71 \\
(46.4)\end{array}$ & $\begin{array}{c}82 \\
(53.6)\end{array}$ \\
\hline High & 270 & $\begin{array}{c}91 \\
(33.7)\end{array}$ & $\begin{array}{c}179 \\
(66.3)\end{array}$ & $\begin{array}{c}134 \\
(49.6)\end{array}$ & $\begin{array}{c}136 \\
(50.4)\end{array}$ & 154 & $\begin{array}{c}41 \\
(26.6)\end{array}$ & $\begin{array}{c}113 \\
(73.4)\end{array}$ & $\begin{array}{c}74 \\
(48.1) \\
\end{array}$ & $\begin{array}{c}80 \\
(51.9) \\
\end{array}$ \\
\hline
\end{tabular}

Table 4. Crude and Adjusted Odds Ratios of Opium Regular Use Associated With Selected Characteristics

\begin{tabular}{|c|c|c|c|c|}
\hline Characteristics & Crude $^{\dagger}$ OR $(95 \%$ CI $)$ & $\mathrm{p}$ & Adjusted $\mathrm{OR}^{\ddagger}(95 \% \mathrm{CI})$ & $\mathrm{p}$ \\
\hline \multicolumn{5}{|l|}{ Control type } \\
\hline Visitor controls & Referent & & Referent & \\
\hline Neighborhood controls & $0.77(0.59,1.00)$ & 0.061 & $0.26(0.10,0.69)$ & 0.007 \\
\hline \multicolumn{5}{|l|}{ Gender } \\
\hline Men & Referent & & Referent & \\
\hline Women & $0.20(0.12,0.33)$ & $<0.0001$ & $0.35(0.20,0.61)$ & $<0.0001$ \\
\hline \multicolumn{5}{|l|}{ Age (Years) } \\
\hline$\leq 60$ & Referent & & Referent & \\
\hline$>60$ & $0.81(0.62,1.05)$ & 0.132 & $1.03(0.75,1.41)$ & 0.859 \\
\hline \multicolumn{5}{|l|}{ Place of residence } \\
\hline Kerman city & Referent & & Referent & \\
\hline Non-Kerman city & $1.33(1.02,1.74)$ & 0.033 & $1.40(1.03,1.91)$ & 0.034 \\
\hline \multicolumn{5}{|l|}{ Education } \\
\hline Illiterate & Referent & & Referent & \\
\hline Literate & $0.94(0.69,1.27)$ & 0.706 & $0.95(0.65,1.37)$ & 0.798 \\
\hline \multicolumn{5}{|l|}{ Socioeconomic status } \\
\hline Low & Referent & & Referent & \\
\hline High & $0.88(0.68,1.15)$ & 0.369 & $0.54(0.33,0.88)$ & 0.022 \\
\hline \multicolumn{5}{|l|}{ Cigarette smoking } \\
\hline Non-smoker & Referent & & Referent & \\
\hline Smoker & $6.15(4.60,8.21)$ & $<0.0001$ & $5.49(4.04,7.47)$ & $<0.0001$ \\
\hline
\end{tabular}

$\$$ Adjusted OR was adjusted for gender, age, area of residence, socioeconomic status, and cigarette-smoking.

medical care for a patient they accompany, they may be more willing to discuss opium use with interviewers.

In addition to being more truthful about opium use, visitor controls may have other advantages for case-control studies of illicit drug use. For example, visitor controls may be more likely to provide biological samples, particularly urine samples, in the hospital setting. Because of legal and confidentiality concerns, neighborhood controls are more likely to refuse donating urine or even blood samples. Although opium use itself is not a crime in Iran, possession and storage of opium is a legal matter of concern and a person convicted of possessing 5-kilograms of opium and its derivatives may receive the death penalty (26).

Hospital controls can be selected among hospital visitors or hospitalized patients. A primary disadvantage of using disease control (hospitalized patients) is that their prevalence of opium use is higher than the base population they come from. Opium use has been associated with incresed risk of several diseases $(15,17,18,20)$, or alternatively opium may be used to alleviate pain for various ailments, such as pain from arthritis or cancer (9). Hence, using disease controls can lead to estiamtes of relative risk that are biased toward null.

Our findings are consistent with those of a case-control study of alcohol drinking and breast cancer in which alcohol-drinking was a stigmatized behavior, similar to opium use in our study, whereas cigarette-smoking was not stigmatized in either one. In that study, although the investigators recruited hospital visitor and community-based controls, all analyses were performed on only communitybased controls. They reasoned that using disease controls was a source of bias because cigarette- smoking and alcohol-drinking might mask the association of the risk factors and breast cancer, while the prevalence of cigartte smoking was closer to their target population among hospital 
vistors than disease controls (27). In another study, Frisch et al assessed the association of sexually transmitted infections and anal cancer using disease controls and population controls (28). Population controls were less likely to report high-risk sexual behaviors, while their rates of cigarette- smoking reporting was not statistically different, which may be because of strong tabooed aspects of some sexual behaviors (like visiting female sexworkers, number of partners, and relationships out of family frame) in many societies. Although this study did not use hospital visitor controls in the study design, the findings showed that population controls had reservations about reporting stigmatized behaviors.

In the literature, few studies have used hospital visitors as a source of controls. In the Philippines during 1988 to 1990 , companions of the patients $(\mathrm{N}=125)$ and neighborhood controls $(\mathrm{N}=130)$ were mentioned as the control groups for studying the risk factors of breast cancer (25). Consistent with our findings, cigarette-smoking rates were very close between the 2 series of controls (vistor companion controls $12 \%$ vs neighborhood controls $14 \%$ ), while alcohol-drinking was reported in a smaller percentage by neighborhood controls, drinking alcohol was not a social norm among women; however, the underreporting was not statistically significant (25). Another study focused on organochloride compounds and risk of breast cancer also used visitors as the control group but no other type of controls were recruited for comparison (29). The study did not compare the visitor controls to other types of controls, but the researchers acknowledged that the use of hospital visitors as controls may be a valid and feasible alternative.

Altogether, because of underreporting of opium use among neighborhood controls and high prevalence of opium use among disease controls, visitor controls may be more appropriate than neighborhood controls to study opium as well as other illicit drugs and other stigmatized behaviors, such as certain sexual relationships. However, this needs to be studied and confirmed in future studies. Apart from the exposure, however, control selection needs attention to other pragmatic matters and depends on the research question (30-32).

This study has some strengths. To the best of our knowledge, this was the first study that has investigated the reporting error of opium use in control selection for case-control studies using hospital visitor controls. A notable strength was the high participation rates of both control groups. Furthermore, the same researchers were involved in both studies, which increased the quality and consistency of data collection. The study also has some limitations. The sample size of the hospital visitor controls was small; nevertheless, it was adequate to show the substantial difference of opium use between the 2 control groups.

\section{Conclusion}

In summary, using hospital visitor controls may be a very good choice in case-control studies of opium use, other illicit drugs, and other stigmatized behaviors. These findings should be verified in future studies.

\section{Acknowledgement}

We would like to thank all patients and controls of both case-control studies who took part in this study.

\section{Conflict of Interests}

The authors declare that they have no competing interests.

\section{References}

1. Wacholder S, Silverman DT, McLaughlin JK, Mandel JS. Selection of controls in case-control studies: II. Types of controls. Am J Epidemiol. 1992;135(9):1029-41.

2. Miettinen O. The "case-control" study: valid selection of subjects. J Chronic Dis. 1985;38(7):553-5.

3. Schlesselman JJ. Valid selection of subjects in case-control studies. J Chronic Dis. 1985;38(7):549-50.

4. Feinstein AR. The case-control study: valid selection of subjects. J Chronic Dis.. 1985;38(7):551.

5. Wacholder S, McLaughlin JK, Silverman DT, Mandel JS. Selection of controls in case-control studies: I. Principles. Am J Epidemiol. 1992;135(9):1019-28.

6. Miettinen OS. Individual matching with multiple controls in the case of all-or-none responses. Biometrics.. 1969:339-55.

7. Amin-Esmaeili M, Rahimi-Movaghar A, Sharifi V, Hajebi A, Radgoodarzi R, Mojtabai R, et al. Epidemiology of illicit drug use disorders in Iran: prevalence, correlates, comorbidity and service utilization results from the Iranian Mental Health Survey. Addiction. 2016;111(10):1836-47.

8. Stevens A, Barratt MJ, Lenton S, Ridout M, Winstock A, editors. Social bias in the policing of illicit drug users in the UK and Australia: Findings from a self-report study 2015.

9. Rashidian H, Hadji M, Marzban M, Gholipour M, Rahimi-Movaghar A, Kamangar F, et al. Sensitivity of self-reported opioid use in casecontrol studies: Healthy individuals versus hospitalized patients. PloS One. 2017;12(8):e0183017

10. Ashrafi S, Aminisani N, Soltani S, Sarbakhsh P, Shamshirgaran SM, Rashidi MR. The validity of self-reported drug use with urine test: results from the pilot phase of Azar cohort study. Health Promot Perspect. 2018;8(3):225.

11. Rothman KJ, Greenland S, Lash TL. Modern epidemiology: Lippincott Williams \& Wilkins; 2008

12. Sadeghian S, Darvish S, Davoodi G, Salarifar M, Mahmoodian M, Fallah N, et al. The association of opium with coronary artery disease. Eur J Cardiovasc Prev Rehabil. 2007;14(5):715-7.

13. Davoodi G, Sadeghian S, Akhondzadeh S, Darvish S, Alidoosti M, Amirzadegan A. Comparison of specifications, short term outcome and prognosis of acute myocardial infarction in opium dependent patients and nondependents. J Tehran Heart Cent. 2006;1(1):48-53.

14. Sadeghian S, Graili P, Salarifar M, Karimi AA, Darvish S, Abbasi SH. Opium consumption in men and diabetes mellitus in women are the most important risk factors of premature coronary artery disease in Iran. Int J Cardio. 2010;141(1):116-8.

15. Masoudkabir F, Sarrafzadegan N, Eisenberg MJ. Effects of opium consumption on cardiometabolic diseases.Nat Rev Cardiol. 2013;10(12):733

16. Yousefzadeh G, Shokoohi M, Najafipour H, Eslami M, Salehi F. Association between opium use and metabolic syndrome among an urban population in Southern Iran: Results of the Kerman Coronary Artery Disease Risk Factor Study (KERCADRS). ARYA Atheroscler. 2015;11(1):14.

17. Ghadirian P, Stein G, Gorodetzky C, Roberfroid M, Mahon G, Bartsch $\mathrm{H}$, et al. Oesophageal cancer studies in the Caspian littoral of Iran: some residual results, including opium use as a risk factor. Int $\mathrm{J}$ Cancer. 1985;35(5):593-7.

18. Mousavi MRA, Damghani MA, Haghdoust AA, Khamesipour A. Opium and risk of laryngeal cancer. Laryngoscope. 2003;113(11):1939-43.

19. Shakeri R, Kamangar F, Nasrollahzadeh D, Nouraie M, Khademi H, Etemadi A, et al. Is opium a real risk factor for esophageal cancer or just a methodological artifact? Hospital and neighborhood controls in case-control studies. PloS One. 2012;7(3):e32711. 
20. Afshari M, Janbabaei G, Bahrami MA, Moosazadeh M. Opium and bladder cancer: A systematic review and meta-analysis of the odds ratios for opium use and the risk of bladder cancer. PloS One. 2017;12(6): $\mathrm{e} 0178527$.

21. Nemati S, Rafei A, Freedman ND, Fotouhi A, Asgary F, Zendehdel K. Cigarette and water-pipe use in Iran: Geographical distribution and time trends among the adult population; A pooled analysis of national STEPS surveys, 2006-2009. Arch Iran Med. 2017;20(5):295.

22. Hajipour MJ, Djalalinia S, Sheidaei A, Yoosefi M, Zokaiee H, Damirchilu B, et al. Protocol Design for Large-Scale Cross-Sectional Studies of Surveillance of Risk Factors of Non-Communicable Diseases in Iran: STEPs 2016. Arch Iran Med. 2017;20(9).

23. Farzadfar F, Danaei G, Namdaritabar H, Rajaratnam JK, Marcus JR, Khosravi A, et al. National and subnational mortality effects of metabolic risk factors and smoking in Iran: a comparative risk assessment. Popul Health Metr. 2011;9(1):55.

24. Pourshams A, Saadatian-Elahi M, Nouraie M, Malekshah A, Rakhshani N, Salahi R, et al. Golestan cohort study of oesophageal cancer: feasibility and first results. Br J Cancer. 2005;92(1):176.

25. Ngelangel CA. Hospital visitor-companions as a source of controls for case-control studies in the Philippines. Int $\mathrm{J}$ Epidemiol. 1989;18(Supplement_2):S50-S3.

26. Counter Narcotic Law: Islamic Parliment Research Center of Islamic Republic of Iran; 1988 [cited 2019 June 23rd ]. Available from: http://rc.majlis.ir/fa/law.

27. O'Connell DL, Hulka BS, Chambless LE, Wilkinson WE, Deubner DC. Cigarette smoking, alcohol consumption, and breast cancer risk. J Natl Cancer Inst. 1987;78(2):229-34.

28. Frisch M, Glimelius B, van den Brule AJ, Wohlfahrt J, Meijer CJ, Walboomers JM, et al. Sexually transmitted infection as a cause of anal cancer. N Engl J Med. 1997;337(19):1350-8.

29. Mendonça GAS, Eluf-Neto J. Hospital visitors as controls in casecontrol studies. Rev Saude Publica. 2001;35(5):436-42.

30. Miller A. Hospital or population controls, an unanswered question. J Chronic Dis. 1984;37(5):337.

31. Stavraky KM, Clarke EA. Hospital or population controls? An unanswered question. Journal of Chronic Diseases. 1983;36(4):301-7.

32. Miller AB. Hospital or population controls? It depends on the question. Prev Med. 1994;23(3):263. 